\title{
A ARTE RETÓRICA E A CIÊNCIA DA PAIXÃO
}

Lênia Márcia Mongelli:*

SINTESE - Sabe-se que as Artes Poéticas medievais derivam diretamente da Retórica clássica, a qual, a partir delas, teria desaparecido do cenário medieval para só ressurgir no Renascimento quinhentista. $O$ que este ensaio pretende demonstrar é a permanência, durante a Idade Média, de princípios muito similares aos que os antigos estabeleceram como base da Retórica e de suas ramificações, para além de soluções meramente lingüísticas e gramaticais. $O$ terreno que se escolheu para apontar as analogias é o do lirismo trovadoresco.

PALAVRAS-CHAVE - arte poética, artes medievais, lirismo, trovadores.
ABSTRACT - It is known that medieval Poetics Arts derive straightly from Classical Rhetoric, which are supposed to have been vanished from the medieval scenery to revive only in the Renaissance from XVIth century. What this essay intends to demonstrate is the remaining, during Medieval Ages, of principles very similar to the ones established by the ancients as basis of Rhetoric and its branches, more than merely linguistic and grammatical solutions. The field chosen to point out the analogies is the one of troubadours' lirism.

KEY WORDS - poetical arts, medieval arts, lyricism, troubadours.

Continua instigante o enigma do lirismo trovadoresco, mesmo depois da intensificação de estudos dedicados ao tema desde fins do século XIX e da publicação dos cancioneiros coletivos, que ensejaram as numerosas edições críticas acerca da produção individual de vários trovadores. Qual a origem dessa poesia? Se ainda permanecem válidas as quatro "teses" que apontaram as "fontes" prováveis para o Trovadorismo (a arábica, a médio-latinista, a litúrgica e a folclórica), ${ }^{1}$ de há muito também se constatou que nenhuma delas é suficiente, per si, para abarcar as múltiplas nuanças e as intrincadas veredas de uma poética que vem desafiando as mais lúcidas interpretações. ${ }^{2}$ Delas, há que destacar as pesquisas recentes dos franceses que, marcadamente com os Annales, têm insistido nas relações entre os

* Professora titular de Literatura Portuguesa na Universidade de São Paulo - USP.

1 Dos numerosos autores que abordaram o assunto, pode-se encontrar uma sintese satisfatória em M. Rodrigues Lapa, Lições de Literatura Portuguesa - época medieval, 8. ed. revista e acrescentada, Coimbra, Coimbra Editores, 1973.

2 Num trabalho de 1956, apresentado na USP como tese de Livre-docência, Segismundo Spina já resumia a opinião dos que viram no Trovadorismo a sintese de elementos de várias proveniências (Do formalismo estético trovadoresco, São Paulo, FFLCH/USP, 1966, p. 22).

\begin{tabular}{|l|l|l|l|l|l|}
\hline VERITAS & Porto Alegre & v. 43 & $\mathrm{n}^{\mathbf{0}} 3$ & Setembro 1998 & p. 541-548 \\
\hline
\end{tabular}


os textos literários e as estruturas sociais, ${ }^{3}$ vertente igualmente focalizada por José Mattoso, em Portugal. ${ }^{4}$ Aspectos estilísticos e filológicos são a tônica das publicações entre os italianos (como Giuseppe Tavani) e os espanhóis (como Vicente Beltrán). Tantas linhas de considerações não lograram desfazer o mistério nem reduzir a sedução de poemas tão mais polissêmicos porquanto mascaradamente disfarçados de tautologia temática e de repetitividade paralelística no plano formal. Só bem recentemente é que se vem apreendendo, em toda a sua dimensão, a complexidade simbolística e a densidade metafórica de matrizes, clichês e lugares-comuns de que se serviram, sem a menor cerimônia, os trovadores europeus. ${ }^{5}$

O mais intrigante é que o requintado arsenal estético que sustenta esta enganosa simplicidade não parece provir dos tratados poéticos contemporâneos, ${ }^{6}$ quase todos situados entre a segunda metade do século XII e o XIII e calcados em modelos da retórica e da gramática antigas. Elas darão seus frutos principalmente a partir do século XIV para, combinados com as novidades trazidas pelo Renascimento, produzir a criativa geração do neo-classicismo quinhentista. São, portanto, posteriores à inventividade de Guilherme IX, o duque de Aquitânia, cuja poesia, no século XI, já contém os estereótipos que perpetuarão a identidade do gênero. Mesmo o tratado de amor do andaluz Ibn Hazm, que é de $1022,{ }^{7}$ já se disse conter certas peculiaridades antes próprias de uma concepção oriental das relações amorosas, pouco aplicáveis às cantigas ocidentais e, menos ainda, às galegoportuguesas. Também de muito pouco efeito prático é o De Amore de Andreas Capellanus (escrito entre 1174 e 1186), ${ }^{8}$ cujo conteúdo aponta para o ludismo peculiar ao amor cortês, jogo de salão.

Complementando a perplexidade, ainda se pode raciocinar noutra direção: como se sabe, a base do ensino medieval na Baixa Idade Média continuou sendo a "explicação de textos" calcada na leitura dos autores considerados modelares, auctoritas buscada sobretudo na tradição greco-romana. ${ }^{9}$ Se Cícero e Quintiliano são os formuladores de normas que ainda perduram; se os exempla são extraídos de Homero, Vergílio e da Bíblia, repositório sempre inesgotável, nem por isso são

3 Desse ângulo, é indispensável a leitura das obras de Jacques Le Goff e de Georges Duby, todas de publicação recente no Brasil.

4 Suas obras estão publicadas pela Editorial Estampa, de Lisboa. Um belo exemplo do exame do Trovadorismo à luz de temas sociológicos está em Joäo Soares Coelho e a gesta de Egas Moniz. Portugal medieval - novas interpretaçōes, Lisboa, Imprensa Nacional/Casa da Moeda, 1985.

5 A lista de trabalhos seria infindável. Não deixe de citar-se, contudo, o "feminismo" de teor psicanalitico de $\mathrm{E}$. Jane Burns, The man behind the lady in troubadour lyric. Romance notes, Chapell Hill: University of North Carolina Press, vol. XXV, n. 3, 1985; o discutidíssimo La canción de mujer en la lírica medieval, de Pilar Lorenzo Gradin, Universidade de Santiago de Compostela, 1990; ou, ainda, o capítulo O modelo cortês, com que Georges Duby colaborou no 2. vol. de Histónia de Mulheres - A Idade Média, sob direção de Christina Klapisch-Zuber, Porto, Edições Afrontamento, 1990.

6 Edmond Faral apresentou os mais significativos deles: Les arts poétiques du XIIe et du XIIIe siécle, Paris, Champion, 1962.

7 Ibn Hazm de Córdoba. El Collar de la Paloma, trad. por Emílio Garcia Gómez, Madrid: Alianza Editorial, 1985.

8 Andreas Capellanus. De Amore, ed. bilíngüe, trad. de Inés Creixel Vidal-Quadras. Barcelona: Festin de Esopo, 1985.

9 Emst Robert Curtius. Literatura Européia e Idade Média latina, Instituto Nacional do Livro, Rio de Janeiro: 1957. 
desprezados os poetas provençais, que já sobressaem em excelência estilística nos tratados de Matthieu de Vendôme, de Geoffroi de Vinsauf, de Jean de Garland. Esta curiosa lacuna entre a poesia que se compunha e a "retórica da versificação" que conria paralela ${ }^{10}$ foi apontada com precisão por Carmen Marimón Llorca: “[... ] hasta el nacimiento de las literaturas romances, teoría y práctica poéticas - al contrario de lo que había ocurrido con la predicacion y el dictamen, sus manifestaciones latinas y trascendencia en romance - se distancian y se ignoran. Las artes poetriae, a diferencia de las otras artes non son manuales, ni generadoras de discurso alguno. Son tratados explicabes solo en el ambiente universitario parisino dominado por los lógicos que caracteriza el siglo XIII. Los datos que podamos extraer de ellos son sólo reveladores de una actitud hacia la poesia, pero no de un deseo de reflexionar sobre los auténticos mecanismos de la creación poética."11 São conclusões desse teor, bastante pertinentes, que abrem espaço para outras conjeturas acerca da polivalência do lirismo trovadoresco. Ousemos uma, que já conta com as sugestivas reflexões de Sarah Spence. ${ }^{12}$

É unânime, reforcemos, o reconhecimento de que as artes poéticas medievais estão diretamente entroncadas nos compêndios retóricos da Antigüidade. Edmond Faral aponta três obras específicas como determinantes dessa influência: De inventione, de Cícero; Rhetorica ad Herennium, supostamente de Cornifício e Epistula ad Pisones, de Horácio. ${ }^{13}$ Embora não referida, a Institutio Oratoria, de Quintiliano, também teve papel preponderante. Das cinco partes em que estas obras catalogaram a retórica - inventio, dispositio, elocutio, memoria e actio - com vistas, em última instância, a preparar o cidadão para bem falar nos tribunais, a Idade Média retomou com mais insistência a elocutio, desdobrada em requintamentos estilísticos e dividida em numerosas sub-categoriạs e classificações da linguagem. A mudança foi sensivel: de um conjunto de normas que incluía o aprimoramento tanto do orador quanto do discurso, movidos ambos por elevados fins éticos, passou a ressaitar-se o lado ornamental da eloquiência, o que parecia mais adequado à arte da poesia e aos ademanes graciosos das cortes faustosas da Baixa Idade Média. A amplitude da retórica antiga convergiu para aspectos lingüísticos, com preferência declarada pelas técnicas da amplificação e pelas teorias versificatórias.

Levante-se a questão, num momento em que tanto se discutem as "constantes históricas", por força do interesse pelas "mentalidades" do passado: ao reter e transformar o formalismo dos antigos, teriam os trovadores rompido com aqueles princípios que pareciam datados, porquanto circunscritos aos oradores ou "homens da lei", funcionando os tratados retóricos quase como um "guia prático do advogado"? ${ }^{14}$ Ou o gosto pela controvérsia e pelo debate como desencadeadores

10 Nas palavras de Paul Zumthor. Langue, texte, énigme. Paris: Editions du Seuil, 1975.

11 "Retórica y poética en la Edad Media: apuntes para una teoria composicional del discurso literário. Medioevo y Literatura. Actas del V Congreso de la Associación Hispánica de Literatura Medieval, Granada: 27 septiembre - 1 octubre 1993, 1995, vol. III, p. 179.

12 Rhetorics of Reason and Desire - Vergil, Augustine, and the troubadours. New York: Cornell University Press, 1988.

13 Op. cit., p. 99 .

14 "E como José Perez considera as Instituições Oratórias de Quintiliano. V. sua Introduçāo à obra traduzida ao português por Jerônimo Soares Barbosa. São Paulo: Edições Cultura, 1944, tomo II. 
de uma boa argumentação; a incansável ambição de convencer o ouvinte; a certeza de que "ninguém pode ser orador sem ser homem de bem", etc., são heranças embutidas na nova moda da cortesia? Seria possível que valores tão arraigados tivessem desaparecido da cosmovisão dos cantares galantes?

Na verdade, guardadas as inevitáveis proporções de tempo e espaço, os desígnios dos trovadores são em muitos aspectos análogos aos do orador forense, a exigir, portanto, artifícios persuasórios afins. Por um lado, é preciso considerar que a retórica clássica estabelecia regras para uma literatura eminentemente oral - a levar em conta o gesto, a entonação e até a aparência visual, com mudanças significativas quando as normas incidem sobre o texto escrito; por outro, não há que perder de vista o hibridismo algo teatral da lírica trovadoresca, em que o poema destinava-se a ser cantado e seu alvo constituía-se de um público antes de tudo feminino. Se as circunstâncias eram outras, a substância manteve-se inalterável: convencer o ouvinte, no caso a Dama (sans merci, para dificultar o processo) da "sinceridade" de um amor e de intenções nem sempre confessáveis, a exigir a máxima firmeza na argumentação. Uma vista d'olhos pelas poéticas medievais denuncia o arsenal de estratégias estilísticas à disposição do trovador para se fazer ouvir - com ênfase nos tropos.

Nesse trânsito da Antigüidade para o medievalismo, no que diz respeito à audiência, a utilização da retórica por Santo Agostinho trouxe novidades consideráveis, ${ }^{15} \mathrm{com}$ repercussão direta sobre a arte trovadoresca, às voltas com realidades tão inefáveis quanto as que suscitaram o esforço de entendimento do Santo. Não só o De Doctrina Christiana é sabidamente um guia para se compreender as transformações operadas na retórica clássica; nas Confissões, talvez por seu tom autobiográfico tão encantadoramente pessoal, aplica-se o máximo esforço para ver e fazer ver os mistérios insondáveis da fé e da religião. Todo o livro VII ( $A$ caminho de Deus) é um brilhante emprego da inventio e da dispositio para provar o conhecimento de Deus na memoria. ${ }^{16}$ Pergunta-se: em que a abstração do Amor profano e dos pujantes desejos da Carne exigem menos do amante incauto para se fazer aceito e entendido? Agostinho "sente", empenhado em racionalizar a intuição, as grandezas divinas: "[...] depois de ler aqueles livros dos platônicos e de ser induzido por eles a buscar a verdade incorpórea, vi que 'as vossas perfeições invisíveis se percebem por meio das coisas criadas'. Sendo repelido (no meu esforço), senti o que, pelas trevas da minha alma, não me era permitido contemplar: experimentei a certeza de que existíeis e éreis infinito, sem contudo vos estenderdes pelos espaços finitos e infinitos. Sabia que éreis verdadeiramente Aquele que sempre permanece o mesmo [... ]"; ${ }^{17}$ Fernando Esquio, trovador da nobreza galega dos fins do século XIII, alegoriza o ouvinte de suas coitas e sobre ele destila não mais que dúvidas: 'Esta queyxume te venh' or dizer, / que me non queiras meu sono tolher / pola fremosa de bon parecer, / que de matar home sempr' [á] sabor; / poys

15 O assunto foi exaustivamente tratado por Sarah Spence, na obra citada na nota 12 .

16 Santo Agostinho, Confissóes, 10. ed. Porto: Liv. Apostolado da Imprensa, 1981.

17 Idem, p. 179. 
$m$ ' ela nen hum ben [non/ quis fazer,/ que me queres, Amor?". ${ }^{18} \mathrm{O}$ que fazem ambos senão "mover os afetos", próprios e alheios, em defesa de causas que parecem inacessiveis à sua precária condição humana? Não é a prática legítima da recta intelligentia et definita animi moderatione gubernetum, como se escrevia a Gaius Herennius? ${ }^{19}$

O terreno em que pisam os trovadores é ainda mais escorregadio, porque envolve os brios do homem numa sociedade de "machos"20 que, ao se verem repelidos, alimentam tumultuosos sentimentos de vingança, culpa, rebeldia - difićílimo de serem contidos pelos parâmetros estreitos da ratio retórica. D. Dinis discorreu com maestria sobre a raiva impotente do amante sofredor, a que a disposição formal confere lógica e clareza ao enunciado: "Senhor, que mal vos nembrades / de quanto mal por vós levey / e levo, ben o creades, / que par Deus já poder non ey / de tan grave coyta sofrer! / mays Deus vos leixe part'aver / da mui gran coyta qui mi dades". Por mais simplista que pareça o jogo da vendetta, observe-se que se mantém o decoro no trato e "mesura" na reivindicação da igualdade de direitos. Bom exemplo da mediocritas horaciana, fim último do doutrinário disciplinador concebido pelos antigos.

Passemos a uma outra questão, tão significativa quanto a que se refere à audiência, ao destinatário do canto, de ouvidos pouco dispostos a fazer concessões. Toda a cultura clássica procurou tratar o Amor como meio de elevação do espírito, proposta que se manteve inalterável na transição do paganismo ao cristianismo, diferenciando-se apenas os objetos do culto. Mesmo que já se tenha falado tanto da pouca ou nenhuma influência de Platão na ars amatoria dos trovadores, ${ }^{21}$ muito dada a erotismos antes ovidianos, as palavras de Diotima cruzaram os tempos e as fronteiras, como uma espécie de padrão supra-ético: "Quando das belezas inferiores nos elevamos, através de uma bem entendida pedagogia amorosa, até a beleza suprema e perfeita, que começamos então a vislumbrar, chegamos quase ao fim, pois na estrada reta do amor, quer a sigamos sozinhos, quer nela sejamos guiados por outrem, cumpre sempre subir [...] até que de ciência em ciência, se eleve por fim o espirito à ciência das ciências que nada mais é do que o conhecimento da Beleza Absoluta". ${ }^{22}$ Mesmo o tão irreverente Ovídio defendeu as qualidades da alma sobre as do corpo: "Para seres amado, torna-te digno de tal, para o que não bastará a beleza. Mesmo que sejas Nireu, amado pelo velho Homero, ou Hilas, a da beleza suave, se queres conservar a tua amiga e não queres ter a surpresa de ser abandonado, une os dotes do espírito aos do corpo."23 Ora, não são princípios análogos os que embasam as considerações de Horácio sobre 0 artifex,

18 J. J. Nunes. Cantigas de amor dos trovadores galego-portugueses, Lisboa: Centro do Livro Brasileiro, 1972. (Outras eventuais citaçōes de poemas serão extraidas desta edição).

19 Ad C. Herennius (De ratione dicendi), ed. bilíngüe, trad. inglesa de Harry Caplan. London: Harvard University, 1989, p. 3.

20 Gorges Duby insiste nesse componente decisivo da sociedade medieval: O Cavaleiro, a Mulher e o Padre, trad. de G. Cascais Franco. Lisboa: Publ. Dom Quixote, 1988; Idade Média, Idade dos Homens, trad. de Jônatas Batista Neto. São Paulo: Companhia das Letras, 1989.

21 Allan H. Gilbert. Literary criticism - Plato to Dryden. Detroit: Waine University Press, 1962.

22 "Platão. O Banquete. Diálogos, trad. direta do grego por Jorge Paleikat. São Paulo: Ediouro, s/d, p. 174.

23 Ovídio. A arte de amar, trad. de Célia Pestana, Lisboa, Publicações Europa-América, 1974, p. 40. 
no que se convencionou ser a segunda parte da Epistula ad Pisones, com ecos evidentes nas poéticas medievais que também aderiram ao prodesse e ao delectare? Os efeitos pedagógicos da Arte são paralelos aos da ascensão amorosa: "Já se perguntou se o que faz digno de louvor um poema é a natureza ou a arte. Eu por mim não vejo o que adianta, sem uma veia rica, o esforço, nem, sem cultivo, o gênio; assim, um pede ajuda ao outro, numa conspiração amistosa. Muito suporta e faz desde a infância, suando, sofrendo o frio, abstendo-se do amor e do vinho, quem almeja alcançar na pista a desejada meta."24

Quem não verá aqui o substrato da retórica do amor cortês? ${ }^{25}$ Por razões amplas, de natureza sócio-político-econômicas que fogem ao âmbito deste ensaio, o trovador deve se fazer digno da sua dame-sans-merci - eis o alicerce do sentido que na Occitania constituiu o fino amor. "Objeto cultural" próprio de uma "literatura de evasão", nos termos de Duby, ${ }^{26}$ o sistema amatório da cortesia implicava todo um ritual iniciático a fim de obter o "galardon", prêmio a que aspirava o amante ávido de "ben". As "provas", os "obstáculos" a serem transpostos compuseram um dos mais resistentes estereótipos do lirismo medieval, a ponto de se tornar a pedra-de-toque das novelas de cavalaria. Por exemplo, ainda em 1520, o eminente gramático João de Barros, na sua juvenil Crônica do Imperador Clarimundo, concebeu para o herói da obra a gênese da nação portuguesa; mas a honraria só seria consumada se, além da excelência nas armas, ele conquistasse também a benevolência de Clarinda, esquiva e imprevisível. Tão mais complexa é esta segunda "batalha", que o autor dispende todo o volumoso Livro II para descrever-Ihe os lances tortuosos, perpassados de desânimos e recaídas. Foi a via que se escolheu para fortalecer o espírito de Clarimundo, segundo a mais lídima tradição do doutrinário trovadoresco em prol do futuro perfeito cidadão. O clérigo Ayras Nunes cantou como ninguém as delícias da plenitude interior: " $\mathrm{Ca}$ per Amor cuyd'eu mais a valer, / e os que d'el desamperados son / nunca poderán nen hun ben aver, / mais aver mal, e por esta rrazon / trob' eu e non per antolhança, / mais por que sei mui lealment'amar; / poys min amor non quer leyxar / e dam' esforç' e esperança, / mal venh' a quen sse d'el desasperar."

Se é necessário ser persuasivo e contundente, não só pela transcendência do objeto em causa como pela inacessibilidade do destinatário; se o ardor posto na empreita resulta no fortalecimento de potências anímicas, o instrumental da linguagem há de ser compativel com o quilate da verdadeira contenda em que se digladia o orador / trovador. No seu Tratado da Eloqüência, livro X das Instituições Oratórias, diz Quintiliano: "Igitur eum, qui res invenire et disponere sciet, verba quoque et eligendi et collocandi ratione perceperit, instruamus, qua ratione quod didicerit facere quam optime, quam facillime possit." $27 \mathrm{E}$ todo o capítulo VIII, do livro III, Da Elocução, diz respeito às "figuras" destinadas a "provar", a "mover os

24 Horácio. Epistula ad Pisones. A poética clássica (Aristóteles, Horácio, Longino). Trad. de Jaime Bruna, São Paulo, Cultrix, 1990, p. 67.

25 Apesar dos numerosos estudos recentes dedicados ao assunto, continua válida a sintese de Jean Frappier: Vues sur les conceptions courtoises dans les littératures d'oc et d'oil au XIIe siècle. Cahiers de civilisation médiẹvales, Poitiers, $n^{2}$ 2, p. 136-156, Avril / June, 1959.

O modelo cortês, op. cit., p. 334 e seg.

Trattato d'Eloquenza, $2^{\mathrm{a}}$ edizione, Societá Editrice Dante Alighieri. Roma: 1909, p. 10. 
afetos" e a "deleitar", dispositivos quintessenciados pelas poéticas medievais, então às voltas com as complexidades da métrica, do rítmo, da versificação. A ênfase recai nos chamados "ornamentos de estilo", em que o "fácil" e o "difícil" repõem, num certo sentido, os famosos três gêneros da Roda de Vergílio. ${ }^{28}$ Como agora, nos meios cortesãos, está em causa não só a elocução, mas a própria dignidade social do orator, os tropos são indispensáveis ao refinamento do discurso. Metáforas, antíteses, metonimias, perífrases e alegorias constituem alguns dos segredos formais do altíssimo teor simbólico da criação trovadoresca - comprometida com as contradições da casuística amorosa.

Tomemos um recurso argumentativo dos mais caros à Antigüidade: a amplificatio, que, segundo Faral, "les anciens entendaient 'rehausser (une idée), la faire valoir" e "les théoriciens du XIIe et du XIIIe siècle entendent par là "développer, allonger (un sujet)"' ${ }^{29}$ Em qualquer das acepções, que repousa sobre a eficácia demonstrativa e/ou explicativa, o termo parece incompatível com a técnica do paralelismo, predominante no lirismo galego-português e apontado como um dos remanescentes de impregnações folclóricas em material erudito. No entanto, considere-se o belo texto de Roy Fernandiz (Rui Fernandes de Santiago? ${ }^{30}$ ), outro clérigo do século XIII:

Quand' eu vejo las ondas

e las muyt' altas ribas

logo mi veen ondas

al cor pola velyda:

maldito se[j]a l' mare

que mi faz tanto male!

Nunca velj]o las ondas

nen as [muit'] altas rocas

que mi non venhan ondas

al'cor pola fremosa:

maldito selj]a l' mare,

que mi faz tanto male!

Se eu vejo las ondas

e veljlo las costeyras,

logo mi veen ondas

al cor pola ben feyta:

maldito selj]a l' mare,

que mi faz tanto male!

Rigorosamente paralelístico, o texto é à primeira vista monocórdico, compacto, sendo a escassez de variação uma espécie de impedimento à evolução da

28 Edmond Faral, op. cit., p. 86 e seg.

29 Idem, p. 61.

30 Para dados biográficos, consultar António Resende de Oliveira, Depois do espetáculo trovadoresco (a estrutura dos cancioneiros peninsulares e as recolhas dos séculos XIII e XIV). Lisboa: Ediçōes Colibri, 1994. 
queixa. Muitos viram nessa tautologia obsessiva a nota singularizante da "coita" peninsular, ${ }^{31}$ cuja concisão implicaria maior "sinceridade". Por mais discutivel que possa soar a opinião, ela acerta na intensidade dos efeitos que o trovador logra conseguir em tão reduzido espaço, graças a magnífico recurso simbólico. $\mathrm{O}$ quadro repõe arquétipo do imaginário coletivo: a contemplação do mar traz à memória do amante queixoso a sua "velyda", que, ao que tudo indica, o rejeita (maldito). "Ondas" é o dobre retomado pelas rimas, que nos demais versos dão preferência à assonância. Apenas em três pontos das estrofes há alguma variação entre termos de valor sinonímico: "ribas / rocas / costeyra"; "velyda / fremosa / ben feyta"; "Quand'/ Nunca / Se". No mais, a mesma homogeneidade que distingue o refrão.

Contudo, é evidente a extraordinária força expressiva da comparatio: "ondas (do mar) / ondas do cor", tumulto interior provocado pela simples referência às (note-se) qualidades físicas da mulher - num apelo aos sentidos que pouco disfarça a latência de Eros. O ermo da paisagem agreste, escarpada, é cenário adequado à raiva tão mais impotente porquanto solitária e insolúvel na imprecação. A preferência pela forma latina male, em consonância com a sonoridade fonemática de mare (também alatinado), deixa ecoar no estribilho a poderosa metáfora das águas, para que o trovador canalizou todo o seu tormento. No mar, intermediário da amada distante, projeta-se o mistério da paixão.

Em que a amplificatio pôde contribuir para esse retrato da alma, que semelha calculado em pormenores? Está diluída nas partículas adverbiais e conjuntivas "quand", "nunca", "se". À ocasionalidade das expressões temporais, que sugerem ligação menos comprometida entre o "eu" e as "ondas", se contrapõe a urgência condicionalizante do "se" conetivo. Ou seja: o que antes era pura coincidência ou fruto de devaneio à beira-praia, é, ao fim e ao cabo, um olhar de obcecado, que funde mar e mulher no mesmo objeto de desejo insatisfeito. Entre as duas primeiras e a última estrofe, passou-se a eternidade, que é como se medem as horas de um coração preterido.

Em suma, se a retórica dos antigos penetrou pelas poéticas medievais adentro, é porque havia similaridade de intenções a que podiam ser úteis instrumentos apenas adaptados a novos mecanismos sociais - como requer sempre qualquer processo de reatualização (não é o que garante a sobrevivência dos mitos?). Para convencer e bem formar é preciso estar convencido e ser bem formado, o que inspira a clareza e a objetividade da argumentação. Se o receptor da mensagem é um juiz ou a amada, pouco importa quanto ao empenho "retórico" indispensável ao emissor. Mas, havemos de convir, uma coisa é estar diante da impessoalidade de um auditório; outra, bem diferente, é contornar os desacertos da paixão que, implicando e transcendendo o destinatário, reverte sobre o falante. Essa causa tão abstrata exige a mesma e uma outra qualificação dos meios.

31 M. Rodrigues Lapa, op. cit., capítulo O linismo galego-português. 